\title{
Dermatoses in parkinsonism: the importance of multidisciplinary follow-up
}

\author{
Isadora Antunes ${ }^{1}$ \\ Kátia Sheylla Malta Purim ${ }^{1}$ \\ (iD) Luara Leticia Grande \\ Nathália Cristina Alberton ${ }^{1}$ \\ Tatiana Francinne Regis Navarro ${ }^{1}$ \\ Thereza Cristina d'Ávila Winckler ${ }^{1}$
}

1. Positivo University, Rua Pedro Viriato Parigot de Souza, 5300 , Campo Comprido, Curitiba- PR, Brasil

http://dx.doi.org/10.1590/1806-9282.65.6.791

\section{SUMMARY}

Parkinsonism is characterized by bradykinesia with rigidity and/or resting tremor, in addition to non-motor symptoms, which include dermatological manifestations. The objective of this study is to evaluate the main dermatoses in patients with parkinsonism found at the Philanthropic Association of Curitiba - PR. A cross-sectional descriptive study was carried out with the application of a questionnaire and dermatological evaluation of the patients. The sample consisted of 386 patients and was composed mainly by men (55.4\%), between 60-74 years old (51.6\%), with complete primary education (45.3\%), disease diagnosis time between 5-10 years (35\%) and in use of medication (96.6\%). The most prevalent dermatoses were pigmented nevus (36.3\%), warts (25.1\%), actinic keratosis (22\%), seborrheic keratosis (21.5\%), seborrheic dermatitis (20.5\%), and rosacea (19.2\%). Among the 13 cases (3.4\%) of malignant cutaneous neoplasms confirmed by biopsy, 2 were melanomas. Regarding patients' sex, there was a higher prevalence of inflammatory dermatoses (OR 1.64, 95\% Cl 1.08-2.51, $p=0.025)$ and benign cutaneous neoplasms (OR 1.77, 95\% Cl 1.16-2.69, $p=0.01)$ in men. As to age, patients aged between 60-74 years had more pre-malignant skin lesions (OR 2.60, 95\% Cl 1.05-6.44, $p<0.001)$ and seborrheic keratosis (OR 2.52, 95\% Cl 1.02-6.25, $p=0.001)$ and, in those older than 75 years, actinic keratosis was more frequent (OR 5.43, 95\% Cl 2.17-13.6, $p$ <0.001). The results of the study show that it is fundamental to dermatologically evaluate and monitor these patients, aiming at diagnosis and early treatment of lesions, especially of skin cancer.

Keywords: Parkinsonian Disorders. Skin Diseases. Skin Abnormalities.

\section{INTRODUCTION}

Parkinsonism is a generic term that encompasses a set of diseases, all similar in clinical symptomatology, characterized by bradykinesia and rigidity and/or resting tremor. They differ, however, in relation to their pathophysiological mechanisms and basal ganglia affected. The age of the patient is described as the main risk factor for the disease. Furthermore, its incidence is higher in males than in females ${ }^{1-3}$.

Bradykinesia is the most important symptom of the pathology and is essential for the diagnosis. It is caused by the abnormal function of the basal ganglia, resulting in motor disorders, which are characterized by slow movements and of small amplitude. This change is identified by the perception of the following signs: micrographia, lack of dexterity, gait with small steps, hypomimia, and stooped posture. Are also part of the parkinsonism symptomatology: resting tremors, plastic muscle rigidity, and postural instability ${ }^{4.5}$. 
In addition to the motor alterations, parkinsonism also includes non-motor multisystemic symptoms, characterized by cognitive dysfunction and dementia, psychiatric disorders (psychosis and hallucinations), mood and sleep disorders, fatigue, postural hypotension, constipation, bladder dysfunction, alteration of smell and dermatological manifestations; among these, we highlight: seborrheic dermatitis, melanoma, bullous pemphigus, and rosacea ${ }^{6-9}$.

The cutaneous alterations in parkinsonism have been discussed since the beginning of the 20th century, and there is evidence of a causal association between these and the evolution of the disease. This relationship is due to the fact that the $\alpha$-synuclein protein, involved in the physiopathology of the disease, is present both in the central nervous system (CNS) as well as in the skin ${ }^{10.11}$.

The main dermatosis in parkinsonism is seborrheic dermatitis (SD), which, not infrequently, precedes motor symptoms. The first record associating these two conditions was described in 1927. DS is a chronic inflammatory disease that mainly affects areas such as the scalp, hair, face, eyebrows, glabella, nasolabial folds, ears, chest, and folds in limbs ${ }^{11.12}$.

Studies show potential for increased risk of melanoma in parkinsonism due to changes in melanin and its synthesizing enzymes, abnormal apoptosis, besides the fact that both melanocytes and neurons have the same embryological origin ${ }^{13-15}$.

Bullous pemphigus (BP) is an autoimmune disease that affects older people and is characterized by cutaneous pruritus and bullae on erythematous skin, predominantly in the folds of the limbs and trunk. Despite the high prevalence of BP in parkinsonism, their physiopathological link is not yet understood $^{11.16}$.

Rosacea is a common facial dermatosis characterized by persistent facial erythema, edema, stinging, telangiectasies, papules and pustules. Although the link between rosacea and the disease is not fully known, there is evidence to suggest a possible association between them"1.

These skin changes may also arise as side effects of drugs used in the treatment of the disease and are related to their route of administration. These drugs are designed to improve the patient's functional capacity, maintaining the role of dopaminergic neurons. The pharmacological treatment can use anticholinergic medication, MAO inhibitors, dopaminergic agonists, and mainly levodopa. Non-pharmacological therapy must also be associated with physical activity, a diet for constipation, and measures for the prevention of osteoporosis ${ }^{10}$.

\section{METHODS}

A cross-sectional descriptive study conducted by means of a structured and illustrated questionnaire applied by researchers to a sample of adults through simple random selection, after approval and signing of the Informed Consent Form. We obtained data related to sex, age, educational level, time of the parkinsonism diagnosis, pharmacological treatment, and occurrence of dermatoses in the evolution of the pathology. In the case of cognitive impairment of the patient, the questionnaire was applied to their companion and/or person responsible for their care.

After the questionnaire was applied, a dermatological inspection was performed on the patients to assess the presence of active dermatoses, which later were classified, according to their etiology, as inflammatory, infectious, neoplastic, and autoimmune.

We included patients with previously diagnosed parkinsonism and followed-up by APPP, with previously scheduled appointments between 01/12/2017 and 28/02/2018, and excluded patients without no previous diagnosis of parkinsonism, those who refused to participate in the research or to sign the informed consent form and those who did not answer all the questions in the questionnaire.

The project was approved by the Research Ethics Committee (CEP) of the Positivo University under CAAE: 79488117.0.0000.0093. The researchers had received prior training with a dermatologist so that they could recognize and classify the lesions. Even so, in cases of doubt during the diagnosis, they could resort to teleconsulting.

Statistical analyses were performed using IBM SPSS Statistics software v.20.0 and Armonk NY: IBM Corp. The results were described as frequencies and percentages. To evaluate the association between two categorical variables, we used Fisher's exact test or the chi-square test. For associations that presented statistical significance, we estimated the values of the odds ratio (OR) with $95 \%$ confidence intervals, with $\mathrm{p}<0.05$ considered as significant. 


\section{RESULTS}

The sample comprised 386 patients, with a predominance of males $(55.4 \%)$ when compared to females (44.6\%), most of them white. The interviewees were categorized into three groups according to their age: age up to 59 years (17.6\%), between 60-74 years (51.6\%), and 75 years or more (30.8\%). Regarding formal education, $4.9 \%$ were illiterate, $45.3 \%$ has primary education, $27.9 \%$ secondary education, and $22.8 \%$ undergraduate education.

In relation to the time of parkinsonism diagnosis, $22.8 \%$ reported being less than 5 years, $35 \%$ between 5-10 years, $27.7 \%$ between $10-15$ years, and $14.5 \%$ more than 15 years. The predominant profile of the patients is represented in Graph 1.

Most interviewees (96.6\%) declared receiving pharmacological treatment, and the main drugs used were: Levodopa (96.3\%), Pramipexole (41.7\%), and Amantadine (22.7\%).

Of the total sample, 171 patients (44.5\%) reported skin changes after the diagnosis of parkinsonism, and the time when the lesions appeared is described in Table 1. Among the patients who underwent pharmacotherapy, 30\% noticed skin changes after starting the treatment, these included dryness (33.9\%), stains (15.1\%), and pruritus (7\%).

Only $84(21.8 \%)$ of the 386 interviewees associated parkinsonism with the appearance of skin lesions and 55 (14.2\%) believe that their dermatoses are caused by the disease.

When evaluating the dermatological follow-up, $50 \%$ of the study population reported never having consulted a dermatologist. Among those who had already consulted one, $31.9 \%$ said their last consultation was over 12 months ago, $8 \%$ between $6-12$ months, and 10.1\% less than 6 months.

GRAPH 1 - SOCIODEMOGRAPHIC AND CLINICAL PROFILE PREVALENT IN PATIENTS INTERVIEWED ( $\mathrm{N}=$ 386 PATIENTS)

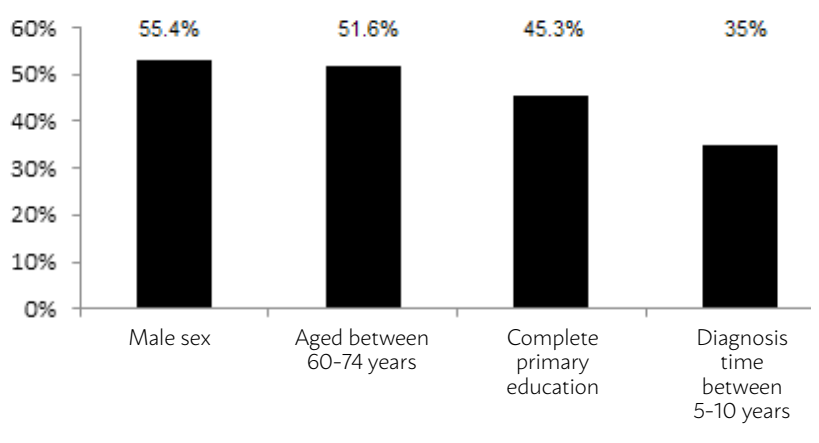

TABLE 1 - RELATIONSHIP BETWEEN THE LESIONS NOTICED BY THE PATIENT AND THE TIME OF THE PARKINSONISM DIAGNOSIS ( $N=171$ PATIENTS)

\begin{tabular}{l|l|l} 
& \multicolumn{1}{c}{ N } & $\%$ \\
\hline Before the parkinsonism diagnosis & 49 & 28.7 \\
\hline$<1$ year after the parkinsonism diagnosis & 19 & 11.1 \\
\hline 1-5 years after the parkinsonism diagnosis & 49 & 28.7 \\
\hline 5-10 years after the parkinsonism diagnosis & 54 & 31.6 \\
\hline Total & 171 & 100 \\
\hline
\end{tabular}

Regarding the dermatoses cited in the literature as frequent in parkinsonism and illustrated in the questionnaire, 16.5\% recognized having had seborrheic dermatitis, $15 \%$ rosacea, $3.6 \%$ melanoma, and $2 \%$ bullous pemphigus.

Upon dermatological inspection, the skin changes most often found were pigmented stains (36.3\%), warts $(25.1 \%)$, actinic keratosis $(22 \%)$, seborrheic keratosis (21.5\%), seborrheic dermatitis (20.5\%), and rosacea $(19.2 \%)$, with different distribution between the sexes.

Of the 11 cases $(2.8 \%)$ of malignant skin neoplasms confirmed by biopsy of the skin lesion, five were squamous cell carcinomas, four were basal-cell carcinomas, and only two were melanomas.

The regression analysis revealed that both the inflammatory dermatoses (OR 1.64, 95\% CI 1.08$2.51 ; \mathrm{p}=0.025)$, mainly the seborrheic dermatitis (OR $1.72,95 \%$ CI 1,03-2,89; $p=0.043)$, and the benign neoplasms (OR 1.77, 95\% CI 1,16-2,69; $\mathrm{p}=0.01$ ), in particular the pigmented nevi (OR 2.04, 95\% CI 1,33-3,14; $\mathrm{p}=0.001$ ), are predominant in males.

We also found that in patients aged 60-74 years, compared to those younger than 60 years, pre-malignant cutaneous lesions (OR 2.60, 95\% CI 1.05-6.44; $\mathrm{p}<0.001$ ) and seborrheic keratosis (OR 2.52, 95\% CI $1.02-6.25 ; \mathrm{p}=0.001)$ were more frequent. Whereas actinic keratosis predominated among those aged 75 years or more (OR 5.43, 95\% CI 2.17-13.6; $p<0.001$ ). In addition, it was evidenced that seborrheic keratosis had a higher prevalence in patients with more than 5 years of diagnostic time (OR 2.18, 95\% CI 1.08-4.39; $\mathrm{p}=0.038$ ).

Comparing the patients who noticed skin changes after the therapy started with those who did not, we found there was a greater incidence of inflammatory (OR 2, CI 95\% 1,25-3,2; $\mathrm{p}=0.005$ ) and infectious dermatoses (OR 1.8, CI 95\% 1,13-2,86; $\mathrm{p}=0.018$ ) in the first group.

With regard to the drugs used by the interview- 
ees, we noticed that Pramipexole was associated to an increased incidence of dermatoses (OR 1.85, CI 95\% 1.16-2.95; $\mathrm{p}=0.012$ ), and Rasagiline with the onset of xeroderma(OR 5.35, CI 95\% 1.53-18.7; $p=0.018$ ).

By means of statistical analysis, no correlation was observed between the occurrence of dermatoses and the level of formal education of the patients.

\section{DISCUSSION}

The sample studied comprised, mostly, men between 60 and 74 years of age; the sex and age were similar to that described for patients with Parkinsonism ${ }^{1.2}$. The low level of formal education found in the present sample is not related to the onset of the disease but represents a characteristic shared by the groups treated by philanthropic institutions.

In relation to the treatment for parkinsonism, most patients use Levodopa, which is considered the drug of choice for the control of symptoms, followed by the Pramipexole, and Amantadine ${ }^{10}$. These medications have among their possible side effects the possibility of cutaneous alterations, as stated in their respective pharmaceutical leaflets. However, to establish a cause-effect relationship, another study design would be necessary.

As expected, a significant portion of the patients reported the onset of dermatoses as adverse symptoms after the beginning of pharmacological therapy. Although Rasagiline is not widely used by these patients, we found that its use was related to a relevant onset of xeroderma, despite this not being described as a possible side effect of the medication. It would be important to conduct new research to verify the causal association between the drug and the symptom.

Considering the perception of the patients regarding the presence of dermatoses, about half of them noticed the onset of cutaneous lesions five years after the diagnosis. Possible explanations for are cutaneous aging, manifestations of parkinsonism or its medications, as well as intrinsic or extrinsic factors of each case. Despite this, only a minority believes there is a connection between parkinsonism and the dermatological changes, evidencing their little knowledge regarding the non-motor symptoms of the disease.

Regarding the dermatoses found during the dermatological inspection, the main ones were pigmented spots, and not seborrheic dermatitis, as described by Ravn et al. ${ }^{11}$. This divergence may be associated with methodological, populational, and/or geoclimatic characteristics.

Common warts, classified as part of the infectious dermatoses, were the second change most often diagnosed and with greater incidence in men. Such manifestations can be transmitted from person to person, through direct or indirect contact, or be influenced by autoinoculation due to skin microtraumas caused by xeroderma pruritus, or even due to immunosenescence ${ }^{17}$.

Although this was not the skin lesion more prevalent in the study, as demonstrated in other publications, seborrheic dermatitis was the fifth dermatosis most found in patients. It is believed that the association between the two diseases is due to the increased secretion of male sex hormones and its resulting effects in the sebaceous glands ${ }^{18}$.

The prevalence of rosacea in this study coincides with that reported in other studies and, although there is no causal relationship between them, they share the same pathogenicity, with high activity of metalloproteinases in the extracellular matrix ${ }^{11.19}$.

After analyzing the malignant skin neoplasms, the results of this study differ from other publications that indicate a reduced incidence of non-melanoma cancers and increased occurrence of melano$\mathrm{ma}^{13-15}$. In this sample, among the suspicious lesions submitted to biopsy, most were diagnosed as squamous cell carcinoma and basal-cell carcinoma.

When comparing the frequency of dermatoses and the sex of the patients, we found a predominance of benign neoplasia and inflammatory dermatoses in males. This finding was attributed to the action of androgens, which increase the activity of the sebaceous gland and, consequently, the inflammatory response $^{20}$.

Taking into account the age of the patients, there was a greater prevalence of premalignant skin lesions in those older than 60 years, which can be explained by the longer exposure to sunlight throughout life. In the same way, seborrheic keratosis, which is a degenerative lesion of keratinocytes, tends to increase in number with the passing of the years.

It is important to highlight that this study presents some limitations, among which its cross-sectional design, the non-probabilistic sampling, and the absence of a control group. The senility of patients may also have generated memory biases. However, this research shows that clinical skills to recognize cutaneous lesions are fundamental in the gener- 
al training of the doctor and necessary in the fight against skin cancer. The need for more research on parkinsonism and its cutaneous manifestations is also highlighted since there is no national paper published on the subject.

\section{CONCLUSION}

In the sample studied, the dermatoses more often found were pigmented spots, common warts, actin- ic keratosis, seborrheic keratosis, seborrheic dermatitis, and rosacea. We also found 11 cases of skin cancer, histologically confirmed, two of which were melanomas. In addition, we found it is fundamental to evaluate and monitor the skin of these patients, aiming at early diagnosis and treatment of injuries, especially of skin cancer. We proposed a multidisciplinary follow-up that includes a dermatologist to enable more comprehensive care to the health of the Parkinsonism patients.

\section{RESUMO}

Parkinsonismo é caracterizado por bradicinesia elou tremor de repouso, além de sintomas não motores, entre os quais se destacam as manifestações dermatológicas. O objetivo desse trabalho é conhecer as principais dermatoses em pacientes portadores de parkinsonismo atendidos em uma associação filantrópica de Curitiba/PR. Foi realizado um estudo descritivo transversal com aplicação de questionário e avaliação dermatológica dos pacientes. A amostra estudada consistiu de 386 pacientes e foi composta principalmente por homens brancos (55,4\%), entre 60-74 anos (51,6\%), ensino fundamental completo (45,3\%), tempo de diagnóstico da doença entre 5-10 anos (35\%) e em uso de medicação (96,6\%). As dermatoses mais encontradas na inspeção dermatológica foram manchas pigmentadas (36,3\%), verrugas (25,1\%), ceratose actínica (22\%), ceratose seborreica (21,5\%), dermatite seborreica (20,5\%) e rosácea (19,2\%). Entre os 11 casos (2,8\%) de neoplasias cutâneas malignas confirmados por biópsia, dois eram melanomas. Em relação ao sexo, houve prevalência em homens de dermatoses inflamatórias (OR 1,64, IC 95\% 1,08-2,51; $p=0,025)$ e neoplasias cutâneas benignas (OR 1,77, IC 95\% 1,16-2,69; $p=0,01)$. Quanto à idade, pacientes entre 60-74 anos apresentaram mais lesões cutâneas pré-malignas (OR 2,60, IC 95\% 1,05-6,44; $p<0,001$ ) e a ceratose seborreica (OR 2,52, IC 95\% 1,02-6,25; $p=0,001$ ); naqueles acima de 75 anos foi mais frequente a ceratose actínica (OR 5,43, IC 95\% 2,17-13,6; $p<0,001)$. Os resultados encontrados no estudo evidenciam que são fundamentais a avaliação e o monitoramento dermatológico desses pacientes, visando diagnóstico e tratamento precoce das lesões, em especial do câncer de pele.

PALAVRAS-CHAVE: Transtornos parkinsonianos. Dermatopatias. Anormalidades da pele.

\section{REFERENCES}

1. Elbaz A, Bower $\mathrm{H}$, Maraganore DM, McDonnell SK, Peterson B|, Ahlskog JE, et al. Risk tables for parkinsonism and Parkinson's disease. J Clin Epidemiol. 2002;55(1):25-31.

2. Taylor KS, Cook JA, Counsell CE. Heterogeneity in male to female risk for Parkinson's disease. J Neurol Neurosurg Psychiatry. 2007;78(8):905-6.

3. Berrios GE. Introdução à "paralisia agitante", de James Parkinson (1817). Rev Latinoam Psicopatol Fundam. 2016;19(1):114-21.

4. Gonçalves LHT, Alvarez AM, Arruda MC. Pacientes portadores da doença de Parkinson: significado de suas vivências. Acta Paul Enferm. 2007;20(1):62-8.

5. Williams DR, Litvan I. Parkinsonian syndromes. Continuum (Minneap Minn). 2013;19(5 Movement Disorders):1189-212.

6. Barone P, Antonini A, Colosimo C, Marconi R, Morgante L, Avarello TP, et al; PRIAMO study group. The PRIAMO study: a multicenter assessment of nonmotor symptoms and their impact on quality of life in Parkinson's disease. Mov Disord. 2009;24(11):1641-9.

7. Hussl A, Seppi K, Poewe W. Nonmotor symptoms in Parkinson's disease. Expert Rev Neurother. 2013;13(6):581-3.

8. Fasano A, Visanji NP, Liu LW, Lang AE, Pfeiffer RF. Gastrointestinal dysfunction in Parkinson's disease. Lancet Neurol. 2015;14(6):625-39.

9. Obeso |A, Stamelou M, Goetz CG, Poewe W, Lang AE, Weintraub D, et al. Past, present, and future of Parkinson's disease: a special essay on the 200th anniversary of the shaking palsy. Mov Disord. 2017;32(9):1264-310.

10. Fernandez HH. 2015 Update on Parkinson disease. Cleve Clin J Med. 2015;82(9):563-8.

11. Ravn AH, Thyssen JP, Egeberg A. Skin disorders in Parkinson's disease: potential biomarkers and risk factors. Clin Cosmet Investig Dermatol. 2017; 10:87-92

12. Krestin $D$. The seborrhoeic facies as a manifestation of post-encephalitic Parkinsonism and allied disorders. Quart J Med. 1927;21(81):177-86.

13. Bertoni JM, Arlette JP, Fernandez HH, Fitzer-Attas C, Frei K, Hassan MN, et al; North American Parkinson's and Melanoma Survey Investigators. Increased melanoma risk in Parkinson's disease: a prospective clinicopathological study. Arch Neurol. 2010;67(3):347-52.

14. Ong EL, Goldacre R, Goldacre M. Differential risks of cancer types in people with Parkinson's disease: a national record-linkage study. Eur J Cancer. 2014;50(14):2456-62.

15. Wirdefeldt K, Weibull CE, Chen H, Kamel F, Lundholm C, Fang F, et al. Parkinson's disease and cancer: a register-based family study. Am J Epidemiol. 2014;179(1):85-94.

16. Schmidt E, Zillikens D. Pemphigoid diseases. Lancet. 2013;381(9863):32032.

17. Leto MGP, Santos Junior GF, Porro AM, Tomimori J. Infecção pelo papilomavírus humano: etiopatogenia, biologia molecular e manifestações clínicas. An Bras Dermatol. 2011;86(2):306-17.

18. Sampaio ALSB, Vargas TIS, Nunes AP, Mameri ACA, Ramos-e-Silva $M$, Carneiro SCS, et al. Dermatite seborreica. An Bras Dermatol. 2011;86(2):306-17.

19. Fischer M, Gemende I, Marsch WC, Fischer PA. Skin function and skin disorders in Parkinson's disease. J Neural Transm. 2001;108(2):205-13.

20. Tagliolatto S, Alchorne MMA, Enokihara M. Hiperplasia sebácea cutânea: estudo piloto para a correlação da doença com hormônios androgênios. An Bras Dermatol. 2011;86(5):917-23. 